\title{
HVDC (High Voltage Direct Current) Transmission System: A Review Paper
}

\author{
${ }^{1}$ Abhishek Kumar \\ Sharda University, India \\ 1abhishekmth97@gmail.com
}

\author{
${ }^{2}$ D. M. Akbar Hussain \\ Aalborg University, Denmark \\ 2akh@et.aau.dk
}

\begin{abstract}
Back in the early days of electricity supply, AC (alternating current) was adopted for power transmission because it could be stepped up or down as needed by transformers and because it could be interrupted more easily than DC (direct current). High-voltage AC grids evolved as an efficient way to connect existing islands of distribution grids and large generation units with industrial and residential loads. It was not until some decades later that the technology for high voltage DC (HVDC) power advanced sufficiently for the first commercial HVDC link to be established. This paper reviews current \& future of HVDC transmission systems in India. The article discusses the recent developments in HVDC Transmission \& other technologies in India \& World also. This paper compares the HVDC transmissions design, operation, construction and maintenance over HVAC. The article additionally shows an economic analysis of HVDC transmission innovation over an AC framework in India. This paper gives a review of references formations of HVDC transmission frameworks in India. The paper conclusions why picking HVDC frameworks in the present power framework development.
\end{abstract}

Keywords: HVDC Links, Bipolar Transmission, Transmission

1. HVDC History:-

In a year, The first HVDC transmission was inaugurated in Miesbach-Munich power transmission in the world, but that time only $1.5 \mathrm{KW}$ power was transmitted. It was built between Miesbach \& Munich in Germany.[16,17]. As we know, the AC system was introduced very quickly for electricity generation, transmission, distribution etc.. [13] The voltage conversion was straightforward in an AC system using Transformer. A transformer is having high electric power and having low losses. Also, The three-phase synchronous generator is very proficient when we compare with DC generator. That's why Transmission is straightforward through an AC System to compare to DC. On the other hand, In long distances transmission and when connected to asynchronous grids, HVAC having few limits.

The Following Table 1 is showing time to time development in HVDC Technology.[1]

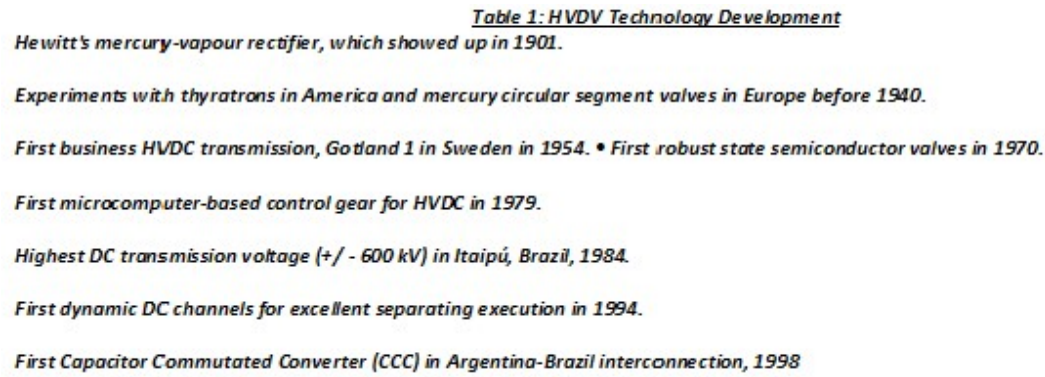

2. Why choose HVDC over HVAC:-

This is an exciting question that why we prefer HVDC over HVAC Because most electricity transmissions use three-phase alternating current. So how HVDC transmission fit into the present power transmission network? The fascinating question is that why we choose HVDC transmission system compare to HVAC whereas most of the threephase electricity transmission uses AC. How will HVDC transmission get success in the present transmission network?

We answer that $\mathrm{AC}$ has been preferred for electrical transmission anywhere, i.e. home, business, in the world, But AC has been some limitation, i.e. it's transmission capacity, long distances, SKIN effect and can never connect between two different frequencies electricity transmission network.[14] The skin effect \& Corona effect tends to less significant for DC \& AC conductors. HVDC transmission is most helpful especially for the interconnection of different frequencies AC grids, also provides high efficiency and control capability. It can be our choice that we go for HVDC power transmission system because DC can able to carry a significant amount of electricity with shallow losses. Another problem with $\mathrm{AC}$ is that most of the renewable generation like solar, hydro and other plants located at populated centres and our choice should be DC for electricity transmission at that places. HVDC is necessary or desirable from a technical point of view.[2][16]

\section{HVDC Transmission Network Component:}

The main components of the HVDC system are mentioned below-Converting Station, Converting Units, Converting Valves, Converting T/Fs, Filters, High-Frequency Filters, Power Source (Reactive), Levelling Reactor, Poles 


\subsection{Converting Station:}

At the substation, Rectifier terminal converts an AC to DC whereas Inverter substation converts DC to AC. Every terminal is designed in such a way that they work in both mode (Rectifier and Inverter), so then each terminal is known as converter terminal. A two-terminal HVDC transmission system is having two terminal and one HVDC line. The following Fig. (1) is showing A Typical HVDC Converter Station:

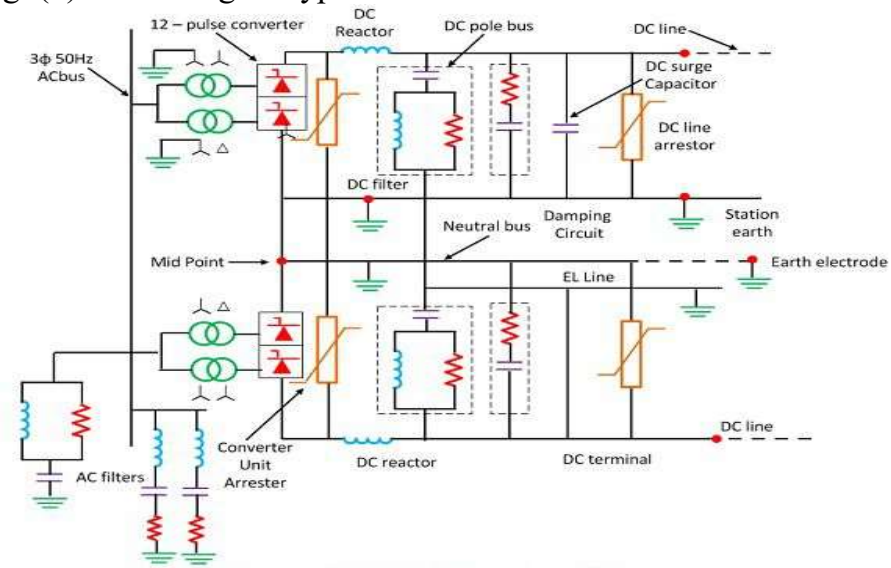

3.2 Converting Unit:

Fig (1).- Schematic Diagram of A Typical HVDC Converter Station [3]

As we discuss, converter unit converts $\mathrm{AC}$ to $\mathrm{DC}$, and its vice-versa is used at three-phase bridge converters. This circuit is also known as Graetz Circuit. There is 12-pulse bridge converter is used in HVDC transmission, and that converter obtains by connecting two or 6-pulse bridge converter as shown in figure[2].

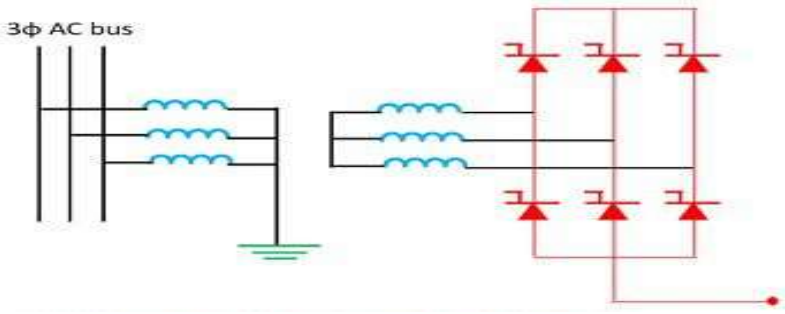

Fig. (2).- 6-Pulse Converter Unit [3]

3.3 Converting Valves:

However new HVDC converter uses 12-pulse converter units and the total number of valves in each group shown in figure 3. Thyristor based modules are used to make series connection valves. The amount of thyristor valve depends upon the required voltage across the valve.

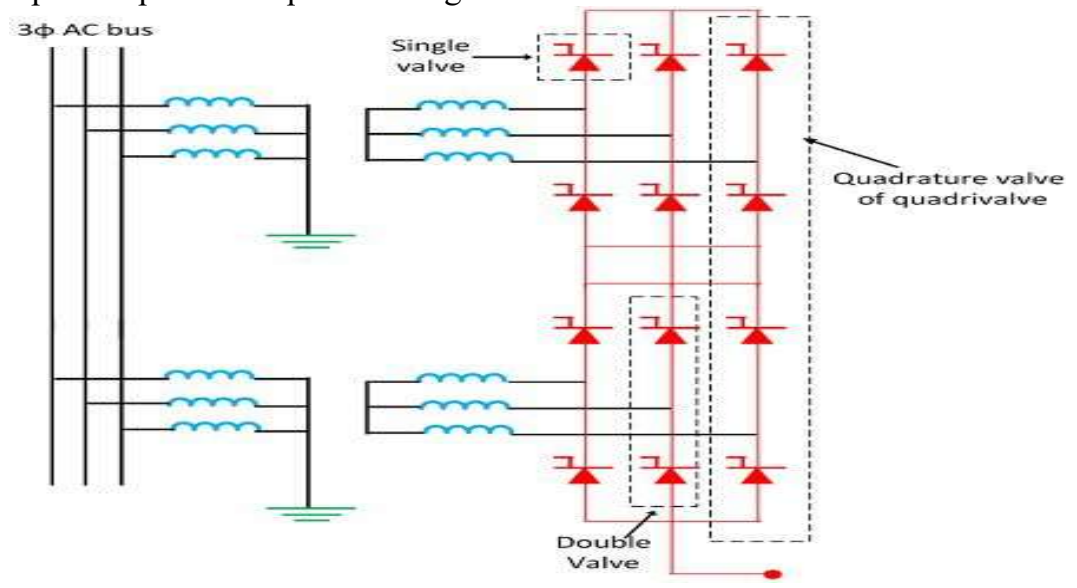

Fig. (3).- 12-Pulse Converter Unit [3]

3.4 Converting T/Fs:

The converter transformer changes over the AC to DC systems or the other way around. They have two arrangements of three stage windings, First is AC side winding and second is Valve sidewinding. The converter can work with 12 heartbeats for each cycle in the AC supply utilising Star-Delta and Wye-Delta Connection of $\mathrm{T} / \mathrm{F}$, which wipes out various consonant current. Anyway here whirlpool current misfortunes are increments because of the music current. The magnetisation in the centre of the converter transformer is a result of the accompanying reasons.

As we probably are aware, the converter transformer used to change over $\mathrm{AC}$ to $\mathrm{DC}$ and furthermore $\mathrm{DC}$ to $\mathrm{AC}$. They have three stage winding, one is called an $\mathrm{AC}$ winding, and the other is Valve sidewinding. The converter worked with 12-heartbeat in every cycle in AC supply utilising star-delta and delta-star association of T/F, which 
expels various symphonious current, anyway here whirlpool current misfortunes are expanding because of sounds current. The charge in converter T/F centre is a result of the following reasons:-:-[17]

a) The AC arrange containing sounds.

b) The coordinate voltage from the valve side terminal additionally has a few musics.

3.5 Filters:-

Filtration of Harmonics is exceptionally essential and furthermore for generation of receptive power at line cumulative converter station. The AC and DC sound music is infused into AC and DC lines separately. The music has the accompanying focal points. Filtration is almost obligatory for generation of reactive power at range expanding converter station. The AC and DC sounds are infused at AC and DC line separately. The sounds have following inconveniences:

a. It obstructs phone lines.

b. Due to the sounds, the power misfortunes in machines and capacitors are associated in the framework.

c. The sounds delivered reverberation in an AC circuit bringing about finished voltages.

d. Instability of converter controls.

The music is limited by utilising the AC, DC and high-recurrence channels. The kinds of networks are - AC Filters, DC Filters, \& High-Frequency Filters.

3.6 Power Source (Reactive):-

Converter tasks are required Reactive power. Extra power can likewise be accomplished from the synchronous stage modifiers of shunt capacitors and static var frameworks. The decision relies upon the coveted control speed.

3.7 Levelling Reactors:-

The smoothing reactor like as oil cooled reactor stuffed with high inductance oil. The converter is associated with this reactor just before DC. It can be situated at impartial or the line side. The principal motivations behind smoothing reactors:-

I. They ease the swells in the direct current.

II. They diminish the symphonious voltage and current in the DC lines.

III. They constrain the blame current in the DC line.

IV. Consequent compensation disappointments in inverters are avoided by smoothing reactors by lessening the rate of ascending of the DC line in the scaffold when the direct voltage of another arrangement associated voltage breakdown.

V. Smoothing reactors diminish the steepness of voltage and current surges from the DC line. In this way, the weights on the converter valves and valve surge diverters are decreased.

\subsection{HVDC System Pole:}

This is the part of the HVDC transmission system that contains all HVDC substation equipment. It also used for interconnection of transmission lines. In some normal operations, it is having direct forward polarity relative to the ground. Therefore, the pole refers to the DC path that has the same polarity concerning the earth. [12]

\subsection{The medium of Transmission:-}

This overhead line is for the most part bipolar, in other words, two conductors of various polarities. HVDC links are regularly utilised for submerged transmission. The most widely recognised kinds of relationships are healthy and loaded with oil. The solids protection comprises of paper strips impregnated with a high thickness oil and no restriction, e.g. length; presently there are plans accessible at profundities of around thousand meter. The total autonomous oil link is loaded with low thickness oil and keeps on working under strain. The most extreme length for this kind of relationship is by all accounts around $60 \mathrm{~km}$. The new power cable technologies development is increasing in recent years, and a new HVDC transmission cable is now available for underground or underground HVDC power supply. This new HVDC cable is made of extruded polyethene and is used in VSC HVDC based systems [14]

4 Designing, constructing, operating, Maintenance \& Cost structure considerations:-

Generally, It can differ from three years for vast HVDC frameworks given one-year thyristors to HVDC VSC based frameworks running from contract date to dispatching as far as development. The following table 2 demonstrates the experience of various HVDC innovations and the distinctive sort of HVDC with the working time. [4] [1] 
Since the term task alludes to progressing exercises to keep up framework accessibility at composed levels. At present day, HVDC connections can be worked remotely, given the included semiconductor and chip-based control frameworks. There are existing offices without staff. What's more, present-day HVDC frameworks are intended for the unmanned task. This component is especially vital in circumstances or nations where there are few qualified individuals, and these individuals can work various HVDC joins from a focal area. Upkeep of HVDC frameworks is practically identical to that of high voltage AC frameworks. The HV gear at change stations is equivalent to the relating hardware in the $\mathrm{AC}$ substations, and the support can be performed similarly. Upkeep will centre around: AC and DC channels, smoothing reactors, divider infiltrations, valve cooling gear, thyristor valves. In the majority of the over, the time of establishment, start-up and start-up of the task gives satisfactory preparing and support

\section{A) Cost structure:}

The cost of an HVDC framework relies on different elements, for example, transmitted power limit, ecological conditions, kinds of transmission media and other administrative and wellbeing prerequisites, and so forth. Figure 4 demonstrates the cost structure.

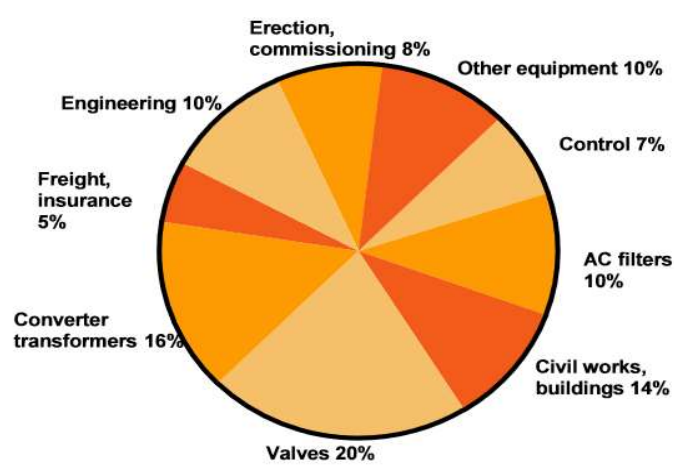

Fig(4).- Cost Structure[1]

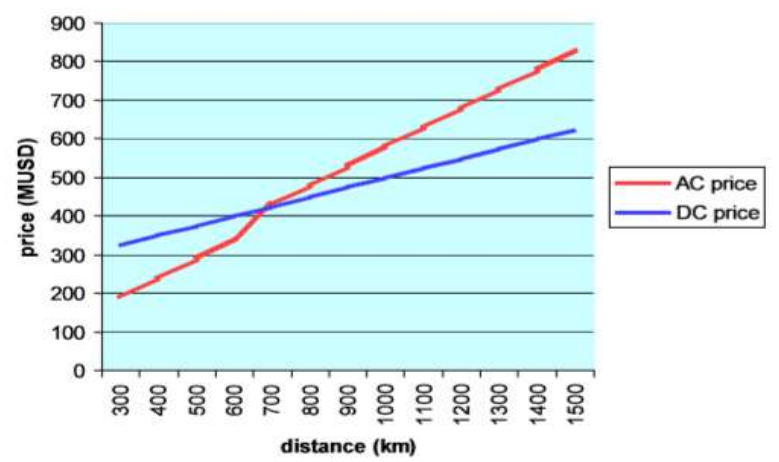

Fig.(5).- price variation for an $\mathrm{AC}$ transmission compared with an HVDC transmission[1]

The price variation for an AC transmission \& an HVDC transmission for $2000 \mathrm{MW}$ is shown below in Fig(5).

For the AC transmission, a two circuit is expected with a cost for each $\mathrm{km}$ of $250 \mathrm{USD} / \mathrm{km}$ (every), AC substations and arrangement remuneration (over $600 \mathrm{~km}$ ) are assessed to 80 MUSD. Bipolar OH line was accepted with a cost for every $\mathrm{km}$ of $250 \mathrm{USD} / \mathrm{km}$; converter stations are evaluated to $250 \mathrm{MUSD}$.[5]

B) Two different examinations are indicating correlation amongst AC and HVDC high voltage frameworks, one is HVDC frameworks and high voltage AC transmission framework, and other is an HVDC framework given VSC and an $\mathrm{AC}$ framework and a nearby age source.

\section{1] Thyristor based HVDC system versus high voltage $\mathrm{AC}$ system:}

HVDC converter stations costs are high when compare with high voltage AC substations. Likewise, working and support costs are brought down in HVDC. Introductory misfortune levels are higher in the HVDC framework, yet don't shift with remove. Despite what might be expected, misfortune levels increment with delete in a high voltage AC framework, as appeared in Fig. (6).

\section{2] VSC based HVDC system versus an AC system:}

VSC HVDC-based frameworks serve low power applications (up to $200 \mathrm{MW}$ ) and generally short range sections (many $\mathrm{km}$ ) of the power transmission range. The accompanying diagram demonstrates that the VSC-based HVDC framework is the best practical other option to a high voltage AC framework as appeared in Figure (7). [5] 

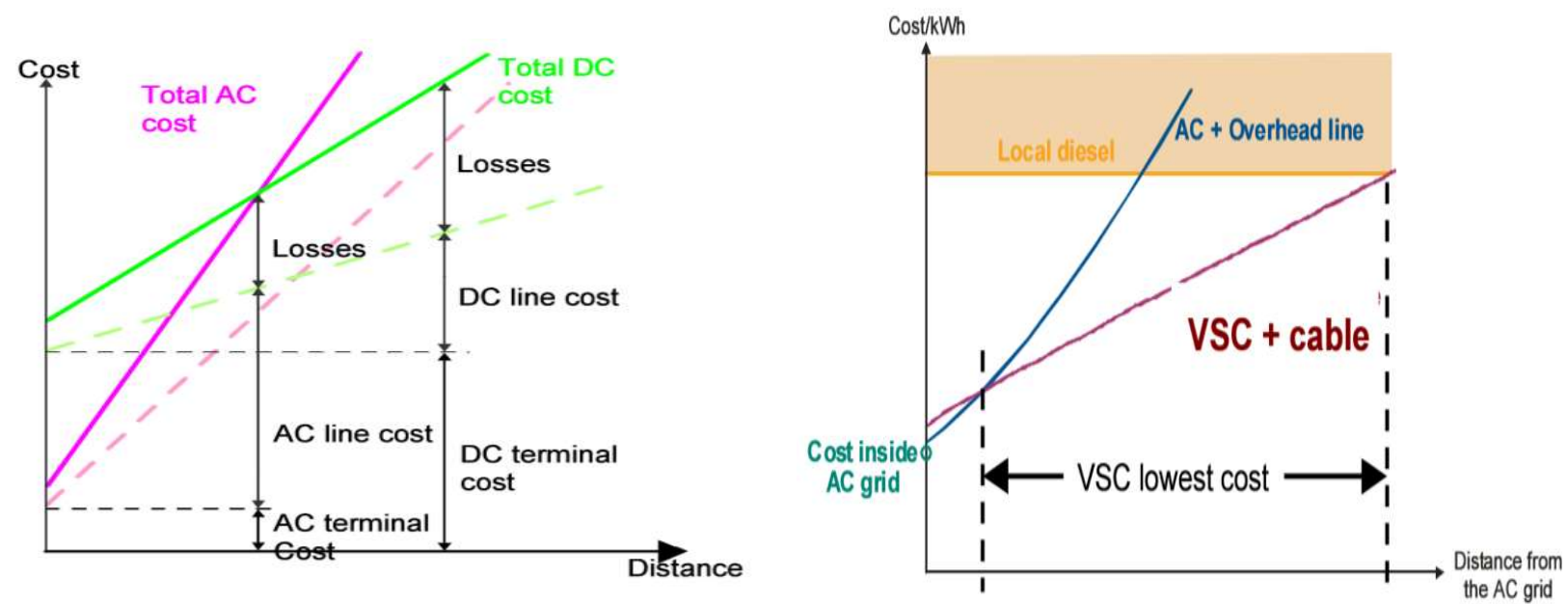

Fig(6): Thyristor based HVDC system [5]

Fig(7): VSC based HVDC system[5]

5 Overview Of HVDC Application:- Following Fig(8) is showing an outline of HVDC application.

\begin{tabular}{|c|c|c|c|c|c|}
\hline & $\begin{array}{l}\text { Long distance } \\
\text { transmission } \\
\text { over land }\end{array}$ & $\begin{array}{l}\text { Long distance } \\
\text { transmission } \\
\text { over sea }\end{array}$ & $\begin{array}{c}\text { Interconnections } \\
\text { of asynchronous } \\
\text { networks }\end{array}$ & $\begin{array}{c}\text { Windmill } \\
\text { connection to } \\
\text { network }\end{array}$ & $\begin{array}{l}\text { Feed of small } \\
\text { isolated loads }\end{array}$ \\
\hline $\begin{array}{c}\text { Natural } \\
\text { commutated } \\
\text { HVDC with } \\
\text { OH lines }\end{array}$ & 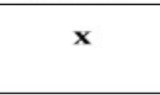 & & 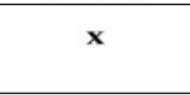 & & \\
\hline $\begin{array}{c}\text { Natural } \\
\text { commutated } \\
\text { HVDC with } \\
\text { sea cables }\end{array}$ & & $\mathbf{x}$ & $\mathbf{x}$ & & \\
\hline $\begin{array}{l}\text { Capacitor } \\
\text { Commutated } \\
\text { Converters } \\
\text { (CCC) in } \\
\text { Back-to-Back }\end{array}$ & & & $\mathbf{x}$ & & \\
\hline $\begin{array}{l}\text { Capacitor } \\
\text { Commutated } \\
\text { Converters } \\
\text { (CCC) with } \\
\text { OH lines }\end{array}$ & $\mathbf{x}$ & & $\mathbf{x}$ & & \\
\hline $\begin{array}{l}\text { Capacitor } \\
\text { Commutated } \\
\text { Converters } \\
\text { (CCC) with } \\
\text { sea cables } \\
\end{array}$ & & $\mathbf{x}$ & $\mathbf{x}$ & & \\
\hline $\begin{array}{c}\text { VSC } \\
\text { Converters in } \\
\text { Back-to-Back }\end{array}$ & & & $\mathbf{x}$ & $\mathbf{x}$ & \\
\hline $\begin{array}{c}\text { VSC } \\
\text { Converters } \\
\text { with Land or } \\
\text { Sea Cables }\end{array}$ & $\mathbf{x}$ & $\mathbf{x}$ & $\mathbf{x}$ & $\mathbf{x}$ & $\mathbf{x}$ \\
\hline
\end{tabular}

Fig. (8).- Overview of HVDC Application [5]

\section{Types Of HVDC Links:}

Generally, there are three kinds of HVDC frameworks. The determination of every structure in the arranging stage relies upon the operational prerequisites, the adaptability of the demand, the issue of consistent quality and the cost. The most well-known HVDC design graphs are as per the following.[15]

a) Monopolar link -

It has a solitary driver of negative extremity and utilizations the land or the ocean for the arrival way of the momentum. In some cases, the metal back is additionally utilised. Here, two converters are set toward the finish of each post. The shafts are grounded utilising ground anodes situated in the vicinity of 15 and 55 $\mathrm{km}$ from the individual terminal stations. Be that as it may, this connection has a few inconveniences since it utilises the earth as a path back. The monopolar interface isn't generally used today. The monopolar interface is appearing in $\operatorname{Fig}(9)$. [5]

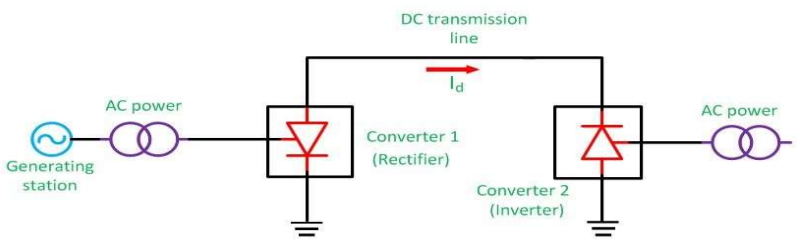

b) Bipolar link-

Fig.9.- Monopolar Link [3]

The bipolar bond has two conductors, one is satisfied and the other negative for the earth. The connection has a transformation station at each end. The midpoints of the converter stations are associated with ground through anodes. The voltage of the terminals associated with the field is just a significant portion 
of the energy of the conductor utilised for the transmission of the HVDC. The most noteworthy preferred standpoint of the bipolar connection is that if any of its connections quits working, the connection progresses toward becoming Monopolar mode because of the arrival to ground. Framework. Half of the structure keeps on providing vitality. These sorts of links are generally utilised as a part of HVDC frameworks. Figure (10) demonstrates the bipolar connection [4].

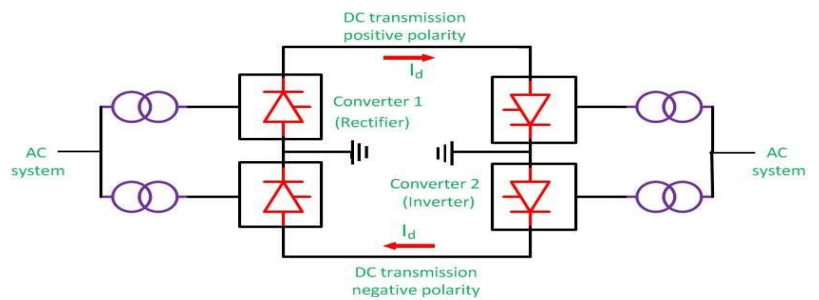

Fig.10- Bipolar Link [3]

c) Homopolar Link-

It has two conductors of similar extremity, ordinarily of negative extremity, and dependable works with a mass or metallic return. The shafts work in parallel in homopolar connection, which decreases the cost of protection. The homopolar framework isn't utilised at present. Figure 11 demonstrates the homopolar security.

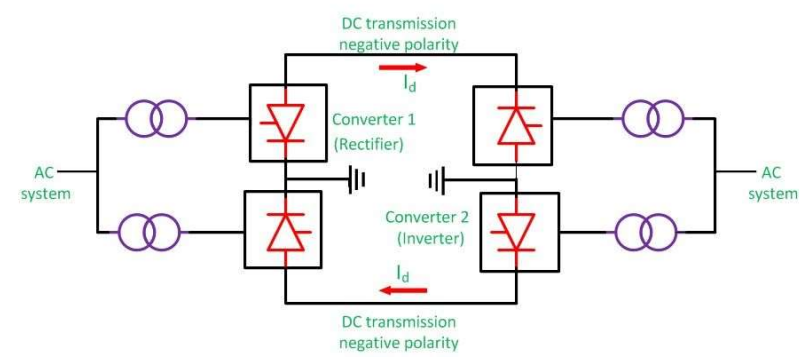

Fig.11- Homopolar Link [3]

d) Long-distance Transmission:-

This kind of transmission is connected when the voltage to be conveyed is high, and the separation between both AC stations is more than make back the initial investment remove. Fig. 12 is demonstrating the Long separation HVDC transmission system.[5]

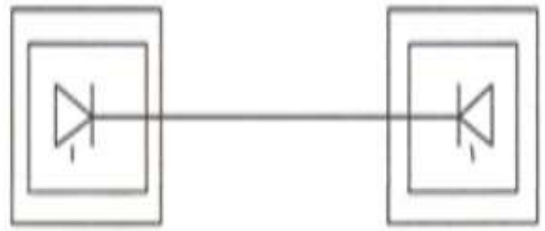

Fig.12- Long Distance Transmission [3]

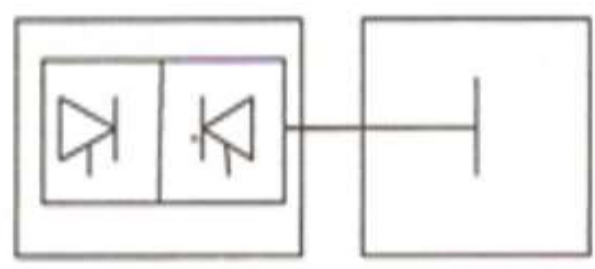

Fig.13-Back To Back Transmission [3]

e) Back to Back Transmission:-

This type of transmission is connected when the voltage to be conveyed high, and the two stations work at various frequencies. Consecutive The HVDC transmission framework appears in Fig.13.

$7 \quad$ HVDC TRANSMISSION IN INDIA: Following Fig.14 is showing HVDC Transmission Existing in India.[6][10] 


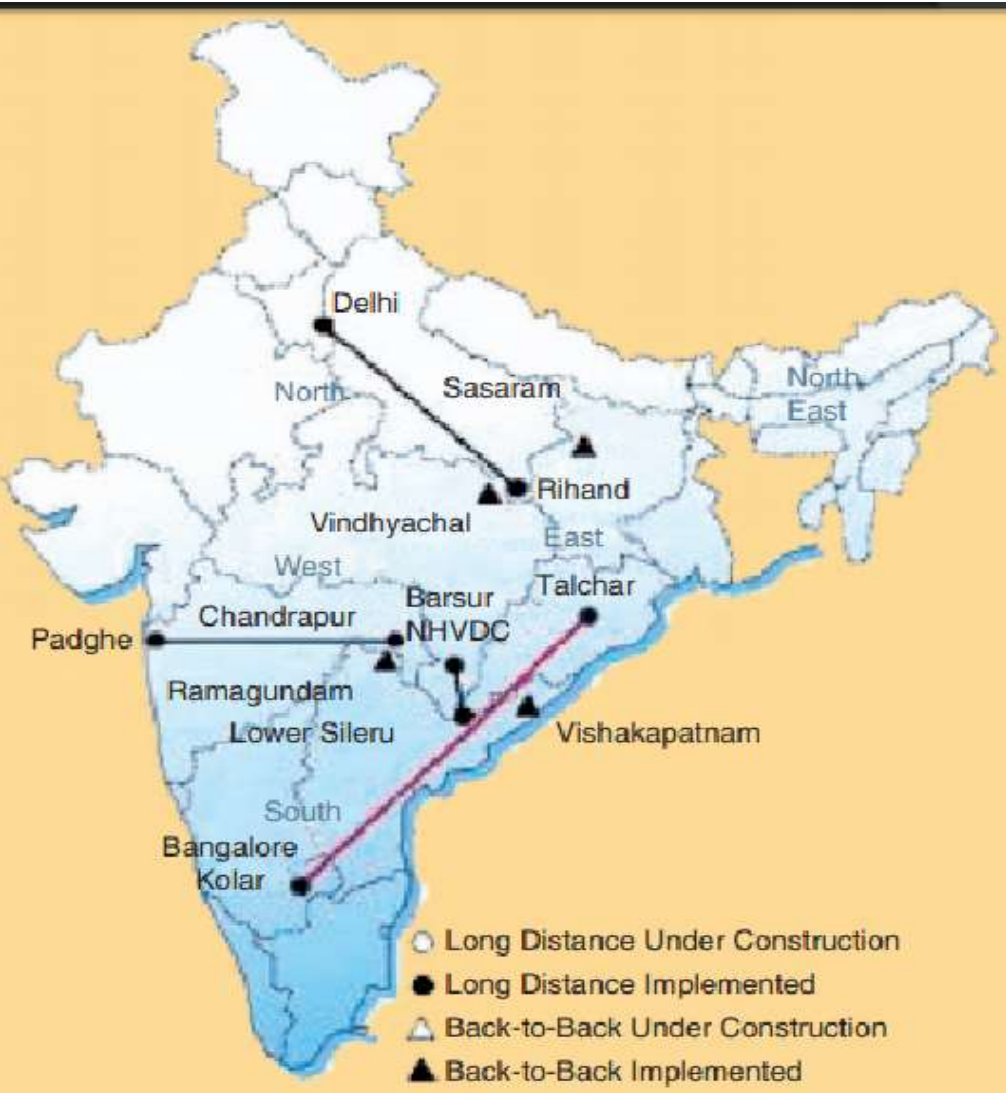

\begin{tabular}{|c|c|}
\hline a) Bipole line & $\begin{array}{l}\text { Circuit } \\
\text { kilometers }\end{array}$ \\
\hline Chandrapur-Padghe (1999] & 1,504 \\
\hline Rihand-Dadri (1990) & 1,634 \\
\hline Talcher-Kolar [2002] & 2,738 \\
\hline Balia-Bhiwadi (2009) & 1,800 \\
\hline Biswanath-Agra [2014] & 3,600 \\
\hline b) Bipole transmissian capacity & MWN \\
\hline Chandrapur-Padghe [1999] & 1,500 \\
\hline Rihand-Dadri (1990) & 1,500 \\
\hline Talcher-Kolar [2002] & 2.500 \\
\hline Balia-Bhiwadi (2009) & 2,500 \\
\hline Biswanath-Agra (2014) & 4,000 \\
\hline $\begin{array}{l}\text { c) Back-ta-back transmission } \\
\text { capacity }\end{array}$ & MW \\
\hline Vindhachal (1989) & 500 \\
\hline Chandrapur (1999) & 1,000 \\
\hline Gazuwake [2009] & 1,000 \\
\hline Sasaram [2002] & 500 \\
\hline Vizag [1990] & 500 \\
\hline $\begin{array}{l}\text { d) Monopole line Barsur-Lawer } \\
\text { Sileru (2000)-16:2 circuit } \\
\text { kilometer }\end{array}$ & 200 \\
\hline $\begin{array}{l}\text { e) Monapole transmission } \\
\text { capacity Barsur-Lower Sileru } \\
\text { (2000] }\end{array}$ & 200 \\
\hline
\end{tabular}

Fig14.- HVDC Transmission In India [6]

(1) Dadri HVDC Project: Below Fig. 15 \& Table 3 is showing details of this project.

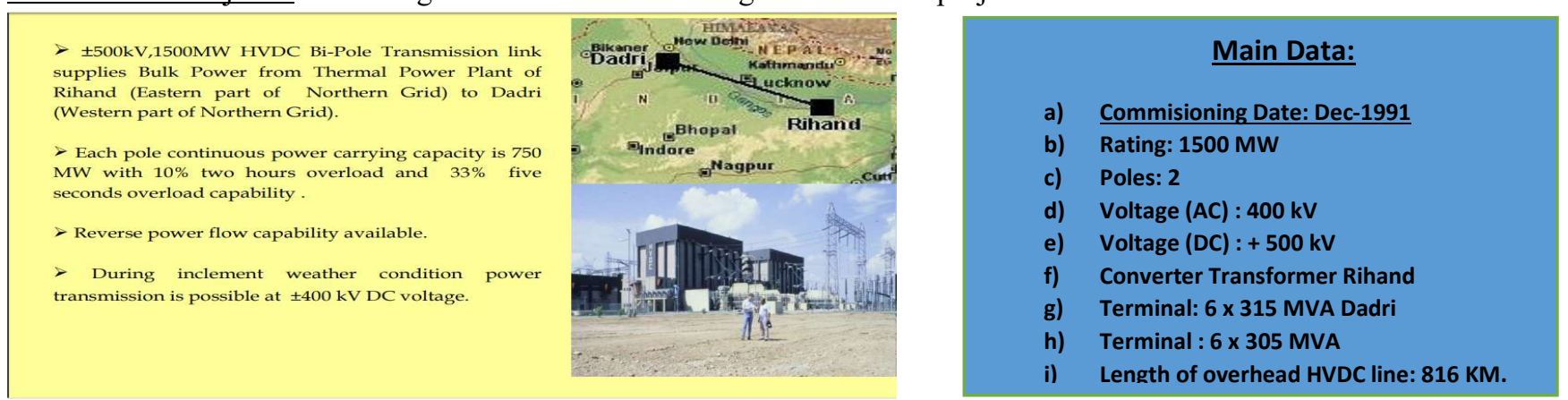

Fig.15.- Dadri-HVDC Bi-Pole Transmission Link [10]

2) Vindhyachal Back to Back Station:

Table 4 is showing details of this project.

\section{Main Data:}

a) Project Completing Date: April 1989

b) Power rating : $2 \times 250 \mathrm{MW}$.

c) Blocks : 2

d) Voltage (AC): $400 \mathrm{kV}$

e) Voltage (DC): $\pm 70 \mathrm{kV}$

f) Converter Transformer : 8 × 156 MVA

Table 4- Vindhyachal Back to Back Station Project Details.[10]
Table 3.- Dadri HVDC Project Details[6]

3) Chandrapur Back to Back Station:

\section{Main Data:}

a) Starting date: November 1993

b) Completing period: Dec 1997

c) Power rating: $2 \times 500 \mathrm{MW}$.

d) Blocks : 2

e) Voltage (AC) : $400 \mathrm{kV}$

f) Voltage (DC) : $205 \mathrm{kV}$

g) Converter Transformer : 12 × 234 MVA

Table 5 - Details of Chandrapur Back to Back Station Project Details.[10] 
4) Talchar - Kolar Transmission: -

The longest commercial HVDC link in India

is Talchar-Kolar transmission, the distance around

(1369 Km.). Table 6 is showing details

of above project.

project:

System Salient Features:

Main Data:
a) Completing date: June 2003
b) Power rating : $2000 \mathrm{MW}$
c) Poles : 2
d) Voltage (AC): $400 \mathrm{kV}$
e) Voltage (DC): + $500 \mathrm{kV}$
f) Converter Transformer at Talcher : 6 × 398
g) Kolar : $6 \times 398$ MVA

Table 6.- Talchar-Kolar Transmission Project Details[10]

Project Details [10]

6) Gazuwaka Back to Back Station:

This transmission line is connected between Jeypore (Eastern Region) to Gazuwaka (Southern Region) Thermal Power Stations of Indian Grid.

Following Table 8 is Showing details of this Project:-

Main Data:
a) Completing date: $1^{\text {st }}$ Block: Feb $1999,2^{\text {nd }}$ Block: March 2005
b) Power rating: $2 \times 500 \mathrm{MW}$.
c) Blocks : 2
d) Voltage (AC) : $400 \mathrm{kV}$
e) Voltage (DC) : $205 \mathrm{kV}$ in $1^{\text {st }}$ Block and
i. $177 \mathrm{KV}$ in $2^{\text {nd }}$ Block,
f) Converter Transformer: $1^{\text {st }}$ Block : $6 \times 234 \mathrm{MVA}$
$1.2^{\text {nd }}$ Block: $6 \times 201.2 \mathrm{MVA}$

Table 8.- Details of Gazuwaka Back to Back Station [10]

\section{Advantages of HVDC over AC transmission:}

Today, HVDC frameworks join the vast experience of the old establishments with as of late created advancements and materials. The result is an extremely focused, adaptable and productive method for transmitting electrical vitality with a low natural effect. Remark that an HVDC framework not just transmits electrical power starting with one point then onto the next, but it has a great deal of significant worth included which ought to have been essential to understanding by another method on account of utilising a regular AC transmission.

\section{Some of these aspects are:-}

a. Cost of transmission is less since only two conductors are used for transmission.

b. There is no reactive power. So transmission losses are reduced.

c. For for the same power current is less due to high voltage transmission. So $I^{2} \mathrm{R}$ loss is very less.

d. There is no skin effect just because of DC transmission, So thin conductors can be used. Whereas the thick conductors must be used to eliminate skin effect In case of HVAC transmission.

e. Two AC frameworks having distinctive frequencies can be interconnected utilising HVDC transmission lines. This isn't conceivable in HVAC transmission framework.

f. Installation cost is less. Because of just two conductors and littler towers required for HVDC.

g. HVDC utilises electronic converters. So Protections, blame freedom can be actualised quicker than HVAC. Thus DC transmission framework has enhanced transient steadiness.

h. In the instance of issues, control levels on HVDC framework can be controlled electronically (i.e., quick). 
i. Since HVDC requires no charging current and the active power, it is favoured in control transmission through links.

j. Unlike the HVDC transmission framework, HVAC actuates body streams in the region of the conductors.

k. HVDC transmission does not have any dielectric misfortune warming issues in the protection of conduits.

l. HVDC has the least discernable clamour and additionally least radio, TV impedance.

m. Due to bipolar transmission, the voltage levels are adjusted regarding earth.

n. DC links utilised for transmission are less expensive than AC links.

o. In HVDC, line charging and electric reverberation don't present which prompts high-productivity.

The disadvantage of HVDC Transmission

a. High cost changing over and altering supplies are required for HVDC transmission. So it is uneconomical for low power supply over short separations.

b. Converters control is very mind-boggling.

c. Additional channels are required at different phases of an HVDC transmission framework. So it is prompt high establishment cost. [7][8]

9 HVDC Technology in Electricity Industry:-

The question is regularly asked in the matter of when should HVDC transmission be picked over an AC framework. Before, traditions were that HVDC was chosen when :

1. Broad measures of intensity $(>500 \mathrm{MW})$ should have been transmitted over long distances $(>500 \mathrm{~km})$;

2. Transmitting force submerged;

3. Interconnecting two AC arranges in a nonconcurrent manner.[9]

4. HVDC frameworks remain the best sparing and naturally benevolent choice for the above customary applications. Be that as it may, three unique elements - innovation improvement, deregulation of power industry around the globe, and a quantum jump in endeavours to moderate the earth - are requesting an adjustment in believing that could make HVDC frameworks the favoured different option to high voltage AC frameworks in numerous different circumstances also. To expound:

5. Innovations, for example, the VSC based HVDC frameworks, and the new expelled polyethene DC links have made it workable for HVDC to end up financial at bringing down power levels (up to $200 \mathrm{MW}$ ) and over a transmission separation of only $60 \mathrm{~km}$.

6. Liberalization has expedited different requests the power foundation generally. Transmission is presently a contracted administration, and there is next to no space for deviation from contracted specific and financial standards. HVDC gives much better control of the power interface and is accordingly a preferred path for giving legally binding transmission administrations.

7. Liberalization has expedited the wonder of exchanging to the power area, which would mean bi-directional power exchanges, contingent upon economic situations. HVDC frameworks empower the bi-directional power streams, which isn't conceivable with AC frameworks (two parallel structures would be required).

8. In the past, when the transmission benefit was a piece of a legislature possessed, vertically incorporated utility, the land securing and acquiring privileges of-way was generally less demanding, and regularly was done under the standard of "Famous Domain" of the State. With progression, transmission benefit arrangement is overall in the space of corporatised, now and then privatised, substances. Land procurement and additionally getting privileges of-way is presently a considerable part of the undertaking's expenses. Once these expenses are incorporated into their sum in the careful investigation of HVDC versus AC options, it would be seen that HVDC is considerably more sparing in such manner, since it requires substantially less land/right-of-route for a given level of intensity.

9. In an ecologically touchy region, for example, national stops and ensured asylums, the lower impression of HVDC transmission frameworks turns into the main plausible approach to manufacture a power connector.

10. So by what means should control framework organisers, speculators in control foundation (both open and private), and agents of such foundation be guided as for picking between an HVDC and a high voltage AC elective? The appropriate response is to let the "market" choose. At the end of the day:

11. The organisers, speculators and lenders should issue useful determinations for the transmission framework to qualified temporary workers, instead of the act of publishing specialised particulars, which are frequently unyielding, and commonly incorporate more seasoned advances and strategies) while welcoming offers for a transmission framework.

12. The practical determinations could set out the power limit, separation, accessibility and unwavering quality necessities; and to wrap things up, the ecological conditions.

13. The bidders ought to be permitted to offer either an HVDC arrangement or an AC arrangement, and the best choice picked. 
14. It is very possible that with changed conditions in the power business, the mechanical advancements, and natural contemplations, HVDC would be the favoured option in numerous more transmission projects [9][11].

10 Conclusion:-

So what is the fate of HVDC? HVDC innovation is (or will be) able to do such establishment, be that as it may, more sides from substantial modern and open spectra should be included to get genuine and most extreme benefit both for the organisations and the general public. In the nearby future, the states will proceed in associating with their neighbours. Then again, more new or present substantial power plants will be at some point or another associated with HVDC (as observed today in India, China, Brazil...). At last, I trust that entire EU will be ,interlaced" with HVDC lines, and afterwards, the subsequent stage will happen - an association of these different lines in a single complex framework.

And if the question is when will this happen? Then my answer is I don't have the foggiest idea. An excessive number of variables are included, and when I see the excruciating procedure which goes with relatively every choice and arrangement inside the EU, it won't be easy...however, I am persuaded, that at some point or another the methods will be made, on the grounds that there are issues which should be tackled and HVDC control framework is one (and possibly the just a single) of the arrangements.

\section{$\underline{\text { References }}$}

[1] High Voltage Direct Current (HVDC)Transmission Systems Technology Review Paper, Presented at Energy Week 2000, Washington, D.C, USA, March 7-8, 2000

[2] new.abb.com > Offerings > HVDC

[3] HVDC Transmission System https://circuitglobe.com/hvdc-transmission-system.html

[4] Transpower Planning Report (Foreword to the Transmission Planning Report 2015) https://www.transpower.co.nz/sites/default/files/uncontrolled_docs/Fleet $\% 20$ Strategy $\% 20-\% 20 H V D C . p d f$

[5] HVDC transmission in India, IEEE POTENTIALS https://www.researchgate.net/publication/261045124

[6] PGCIL: HVDC Systems in India-HVDC Systems presently in operation, Upcoming Projects, Future Challenges, https://sarienergy.org/oldsite/PageFiles/What_We_Do/activities/HVDC_Training/Presentations/Day_1/1_H VDC SYSTEMS IN_INDIA.pdf

[7] Advantages of HVDC over AC transmission, http://www.stopthelines.com/downloads/StevenChuLecture_pg88.pdf

[8] HVDC Advantages, Disadvantages Over HVAC Transmission http://www.completepowerelectronics.com/hvdc-advantages-disadvantages-over-hvac-transmissionsystem/

[9] HVDC Disadvantages http://www.completepowerelectronics.com/hvdc-advantages-disadvantages-overhvac-transmission-system/

[10] HVDC Running Project, HVDC Upcoming Project in India, Future of HVDC in India (PGCIL, NTPC) https://powermin.nic.in/en/content/hvdc-system-india

[11] FUTURE OF HVDC POWER GRID IN EUROPE Technology forecast Vojtech Straka - 1326813

[12] Energy Week 2000, Washington, D.C, USA, March 7-8, 2000 High Voltage Direct Current (HVDC)Transmission Systems Technology Review Paper

[13] A Review of LCC-HVDC and VSC-HVDC Technologies and Applications (https://www.researchgate.net/publication/308778109)

[14] Review of HVDC technology, applications and prospects (https://www.researchgate.net/publication/320957010)

[15] http://www.eirgridgroup.com/site-files/library/EirGrid/Grid-West-HVDC-Technology-Review-ReportPSC.pdf

[16] Guarnieri, M. (2013). "The Alternating Evolution of DC Power Transmission". IEEE Industrial Electronics Magazine. 7 (3): 60-63. doi:10.1109/MIE.2013.2272238.

[17] Donald Beaty et al., "Standard Handbook for Electrical Engineers 11th Ed.", McGraw Hill, 1978 